\section{A Concise Guide to Nuclear Medicine}

\author{
A.H. Elgazzar
}

New York, NY: Springer, 2011, 166 pages, \$39.95

As the name implies, this is a concise manual to current clinical nuclear medicine procedures and techniques. The book is a paperback edition printed on acid-free paper measuring just $9.3 \times$ $6.1 \times 0.3$ in $(\sim 24 \times 15 \times 0.8 \mathrm{~cm})$. It is divided into 11 chapters written entirely by a single author, Dr. Abdelhamid H. Elgazzar from Kuwait University. The first chapter introduces the reader to the basic principles of nuclear medicine, including medical physics, instrumentation, radiopharmaceuticals, and the scope of practice. The subsequent 8 chapters address different organ systems and their specific clinical applications. There are 2 dedicated chapters briefly dealing with nuclear oncology and therapeutic applications of nuclear medicine. Each chapter is preceded by a list of contents for rapid reference, and at the end of each chapter are a quick summary and a section listing further reading material. As is the case with the author's previous publications, this book is well written and the content is up to date. Its major strength lies on the superb illustrations, tables, and diagrams, helping one grasp difficult concepts. The material also includes plenty of images, many of which are in color or extensively annotated. In such a compact format, the book is best suited for medical students, referring clinicians, or radiology trainees in need of a succinct review before a rotation in nuclear medicine. It may also prove to be popular among radiology residents during board preparation. Furthermore, this book should be considered by medical libraries expanding their collection on nuclear medicine.

\section{Gregory Ravizzini}

M.D. Anderson Cancer Center

1400 Pressler St., Unit 1483

Houston, TX 77030

E-mail: gravizzini@mdanderson.org

Published online Sep. 4, 2012.

DOI: 10.2967/jnumed.112.110080

\section{A Practical Guide to Leadership and Management in Academic Radiology}

\author{
R.L. Arenson and C. Garzio
}

Springfield, IL: Charles C. Thomas Publisher, Ltd., 2012, 268 pages, $\$ 37.95$

This book provides valuable guidance for those individuals seeking to become appointed or recently appointed as a chair- person in an academic radiology department. After an introductory chapter, the next 23 chapters describe steps recommended by the authors on the basis of their experience in setting up an internationally recognized academic radiology department at the University of California at San Francisco. The lead author also describes the experiences of other colleagues in academia who have set up similar departments. The benefits derived from reading this book are significant both in teaching individuals from the experience of others and in allowing them to establish their own unique style of leadership. Needless to say, academic politics come into play, and this issue is addressed in the book. Chapter 25, the last chapter, comprises conclusions and a summary.

The various chapters describe the thoughts and actions behind the 3 missions of academic radiology: clinical service, teaching, and research. Supporting these missions are personnel, who create multiple demands in the form of recruitment, incentives, compensation, workload, retention, and morale. In most medical centers, high emphasis is placed on the revenue stream from radiology to support other medical center services. As such, the financial management of the department is of the utmost importance. The issues of billing, joint ventures, capital budget, turf struggles, marketing, and outreach are beautifully described.

Great emphasis is placed on the importance of an excellent information system that connects the radiology system with the medical center system. The authors recommend establishing an information technology team within the department. Other chapters are dedicated to residency and fellowship programs, along with postgraduate education.

This book should be read not only by those seeking to become the chairperson of an academic radiology department but also by those in senior-level leadership who assist the departmental chair. Also, this book is recommended for individuals in the search committee who identify and negotiate with a potential candidate.

Aurelio Matamoros, Jr.

M.D. Anderson Cancer Center

1515 Holcombe Blvd., Unit 1473

Houston, TX 77030

E-mail: amatamor@mdanderson.org

Published online Aug. 29, 2012.

DOI: 10.2967/jnumed.112.112425 